\title{
Influence of Freeze-Thaw Cycles on Mechanical Response of Levee Pavement
}

\author{
Shuan Guo, ${ }^{1}$ Zheng Lu $\mathbb{D}^{2},{ }^{2}$ Guokun Liu, ${ }^{1}$ Baoli Zhuang, ${ }^{1}$ Yongfeng Fan, ${ }^{3}$ and Zuen Zheng ${ }^{1}$ \\ ${ }^{1}$ Hunan Communication Research Institute Co., Ltd., Changsha 410015, China \\ ${ }^{2}$ State Key Laboratory of Geomechanics and Geotechnical Engineering, Institute of Rock and Soil Mechanics, \\ Chinese Academy of Sciences, Beijing 430071, China \\ ${ }^{3}$ Henan Xinrong Expressway Construction Co., Ltd., Luoyang 471000, China \\ Correspondence should be addressed to Zheng Lu; lzwhrsm@163.com
}

Received 30 October 2020; Revised 31 December 2020; Accepted 7 January 2021; Published 27 January 2021

Academic Editor: Valeria Vignali

Copyright (C) 2021 Shuan Guo et al. This is an open access article distributed under the Creative Commons Attribution License, which permits unrestricted use, distribution, and reproduction in any medium, provided the original work is properly cited.

\begin{abstract}
The freeze-thaw cycles cause deterioration in mechanical properties of levee soil and further endanger the pavement structure on the embankment. This study attempts to comprehensively understand the mechanical response of pavement after freeze-thaw cycles. In this paper, the freeze-thaw cycles test under an open system was carried out, and then the triaxial compression test was conducted. Based on the test results, the effects of freeze-thaw cycles, temperature range, initial dry density, and initial moisture content of embankment soil on the mechanical response of road structure after freeze-thaw were calculated and analyzed. Finally, the stability of the slope of the levee was evaluated. The results show that the number of freeze-thaw cycles has the most significant impact on the mechanical response of pavement, the stress and strain of the structural layers vary in different ranges, and the pavement deflection increases by 5 times after 7 freeze-thaw cycles. However, the initial dry density and initial moisture content of the soil have little influence on the pavement structure, and the temperature range will exert an influence when it exceeds a certain threshold.
\end{abstract}

\section{Introduction}

The Songhua River levee is located in the seasonal frozen regions in Northeast China. The parts that pass across the urban area need to be used as the subgrade of urban roads with transportation. Most of the levees are filled with finegrained soil, which is sensitive to frost. Besides, the compaction degree of levees is typically low that will lead to the upward migration of groundwater. Unfortunately, the most important factors in frost heave are presented: frost-susceptible soils, sufficiently freezing temperatures, and water supply [1]. The frost heave in winter and the thawing in summer result in the deterioration of the levee's performance, which causes the uneven settlement of the subgrade and pavement damage under the action of traffic load [2]. In addition, some levee slopes become unstable under the influence of freezing and thawing.

The pavement is most susceptible to the influence of seasonal changes in temperature in road structure, so the mechanical properties of pavement materials after the freeze-thaw cycle are widely concerned $[3,4]$. The pavement performance is mainly influenced by two factors: the vertical deflection that causes rutting and the tensile stress at the bottom of the surface courses that causes cracking [5]. Many scholars have carried out researches on the two aspects. Janoo and Berg [6] studied the bearing capacity of the concrete airport pavement during the spring thawing through the field test and found that the tensile stress at the bottom of the surface layer has a certain relationship with the elastic modulus of the subgrade. Simonsen et al. [7] calculated the response of pavement in the process of freezing and melting based on the mechanical parameters of pavement material and subgrade soil and found that the maximum strain of asphalt surface and subgrade increased about $90 \%$ and $70 \%$ than that before freezing, respectively. Simonsen and Isacsson [8] analyzed the mechanism of cracking and settlement of flexible pavements in the spring thaw. Salour and Erlingsson [9] found that subgrade had a 
greater decrease in the stiffness during the spring thaw than the granular base and subbase. Moreover, the reduction of subgrade performance after freeze-thaw cycles will lead to a serious reduction in pavement bearing capacity [10]. The investigations of subgrade bearing capacity in the literatures mostly focused on the change of elastic modulus $[11,12]$ and the California bearing ratio (CBR) $[13,14]$. According to the results of freeze-thaw indoor tests under the closed system, the elastic modulus of fine-grained soils usually decreases by $50 \%-60 \%$ after freeze-thaw cycles [8]. However, only limited researches involve the changes in the stress and deformation of pavement structure caused by the deterioration of subgrade fill materials after freeze-thaw cycles. And, few researches are studying the mechanical response of pavement caused by the performance degradation of subgrade soil under different initial conditions and different atmospheric temperatures. Actually, the subgrade is the foundation of the pavement structure. The strong and stable subgrade provides an important guarantee for the pavement structure to bear the effect of longterm traffic load. The initial state of subgrade soil (dry density and moisture content), the number of freeze-thaw cycles, and the temperature range all will affect the subgrade performance after freeze-thaw cycles, which certainly lead to different pavement responses [15]. Konrad and Roy [1] considered that the surface heave and longitudinal cracking of pavement were related to the frost susceptibility of subgrade soils from the perspective of geotechnical engineering. Therefore, in order to improve the design level of the pavement in the seasonal frozen regions, it is urgent to study the response of the pavement structure under the deterioration of the mechanical properties in the subgrade after freeze-thaw cycles.

In this paper, the fill soil of Songhua River levee was taken as the research object, and the variations of elastic modulus, cohesion, and internal friction angle of the soil after freezing and thawing cycles are studied by freeze-thaw tests and triaxial compression tests. Then, based on the experiment results, a physical model of pavement-embankment interaction was established to study the influence of embankment performance deterioration caused by freezethaw cycles on the pavement structure.

\section{Experimental Procedure}

2.1. Materials and Sample Preparation. The soil samples used in the test were taken from the levee construction site in the mainstream of Songhua River. The main physical properties are shown in Table 1. The soils can be classified as low liquid limit clay (CL) according to the specification of soil test (SL237-1999). The soil samples were dried and crushed and then were passed through a $2 \mathrm{~mm}$ round-hole sieve. Quantitative distilled water was added to the samples with the required weight and sealed in plastic bags for $24 \mathrm{~h}$. After the moisture content of the soil samples reached the specified value, the soil samples were prepared into cylindrical specimens with $76 \mathrm{~mm}$ height and $38 \mathrm{~mm}$ diameter. The initial moisture content of the specimens was set at $18.2 \%$,
TABLE 1: Basic physical properties of the soil sample.

\begin{tabular}{lc}
\hline Physical index & Data \\
\hline Specific gravity & 2.71 \\
Maximum dry density $\left(\mathrm{g} / \mathrm{cm}^{3}\right)$ & 1.65 \\
Optimum moisture content $(\%)$ & 20.2 \\
Liquid limit $(\%)$ & 38.4 \\
Plastic limit (\%) & 23.5 \\
Plastic index & 14.9 \\
Grain size distribution (\%) & \\
$>0.05 \mathrm{~mm}$ & 4.2 \\
$0.005-0.05 \mathrm{~mm}$ & 61.4 \\
$<0.005$ & 34.4 \\
\hline
\end{tabular}

$20 \%$, and $22.2 \%$ respectively, and the initial dry density was set at $1.50 \mathrm{~g} / \mathrm{cm}^{3}, 1.57 \mathrm{~g} / \mathrm{cm}^{3}$, and $1.63 \mathrm{~g} / \mathrm{cm}^{3}$, respectively.

2.2. Freeze-Thaw Cycle Test. The top and side of the specimen were sealed with plastic film, while the bottom was exposed in order to ensure the water can migrate upwards. The specimen was installed in a nylon cylinder that was installed in the freeze-thaw cycle device. The freeze-thaw cycle device schematic diagram is shown in Figure 1(a). The specimen was frozen and thawed from top to bottom through regulating the temperature (the maximum range of temperature is from $-40^{\circ} \mathrm{C}$ to $40^{\circ} \mathrm{C}$ ) of the circulating alcohol in a steel container at the top of the specimen. The alcohol at the bottom was kept at a constant temperature of about $1^{\circ} \mathrm{C}$. During the freezing, the water was supplied to the specimen through a Mariotte bottle, and no water was supplied during the thawing. The water level in the Mariotte bottle was maintained at the same height as the base of the specimen so that the water could be supplied without pressure. The rubber and plastic foam board was wrapped outside the cylinder to isolate heat exchange. The deformation of the specimen was monitored by the displacement sensor continuously. The 4 freeze-thaw cylinders were integrated together and placed into an environmental chamber with a constant temperature of about $2^{\circ} \mathrm{C}$, as shown in Figure 1(b).

The specimens with the moisture content of $20.2 \%$ were set 3 kinds of dry density to study the effect of initial dry density on the elastic modulus; the effect of initial moisture content on elastic modulus was studied by setting 3 kinds of moisture content for specimens with a dry density of $1.57 \mathrm{~g} /$ $\mathrm{cm}^{3}$. In order to study the influence of temperature ranges and the number of freeze-thaw cycles on the mechanical properties of soil, the specimens with the moisture content of $20.2 \%$ and dry density of $1.57 \mathrm{~g} / \mathrm{cm}^{3}$ were tested under different freeze-thaw cycles and four temperature ranges. The freezing and thawing times were, respectively, chosen as 8 and $4 \mathrm{~h}$ because the temperature inside the samples can reach a stable state after that time period. After each freezethaw test, 4 specimens were taken out from the cylinder and subjected to an undrained unconsolidated triaxial compression test. The axial strain rate of the compression test was $0.5 \% / \mathrm{min}$, and the confining pressures were 50,100 , and $150 \mathrm{kPa}$, respectively. The experimental scheme is shown in Table 2. 


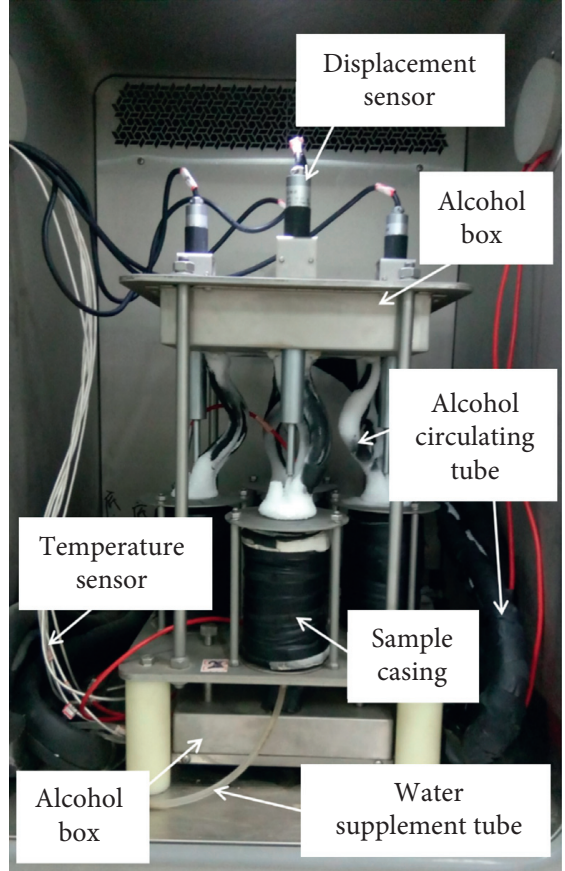

(a)

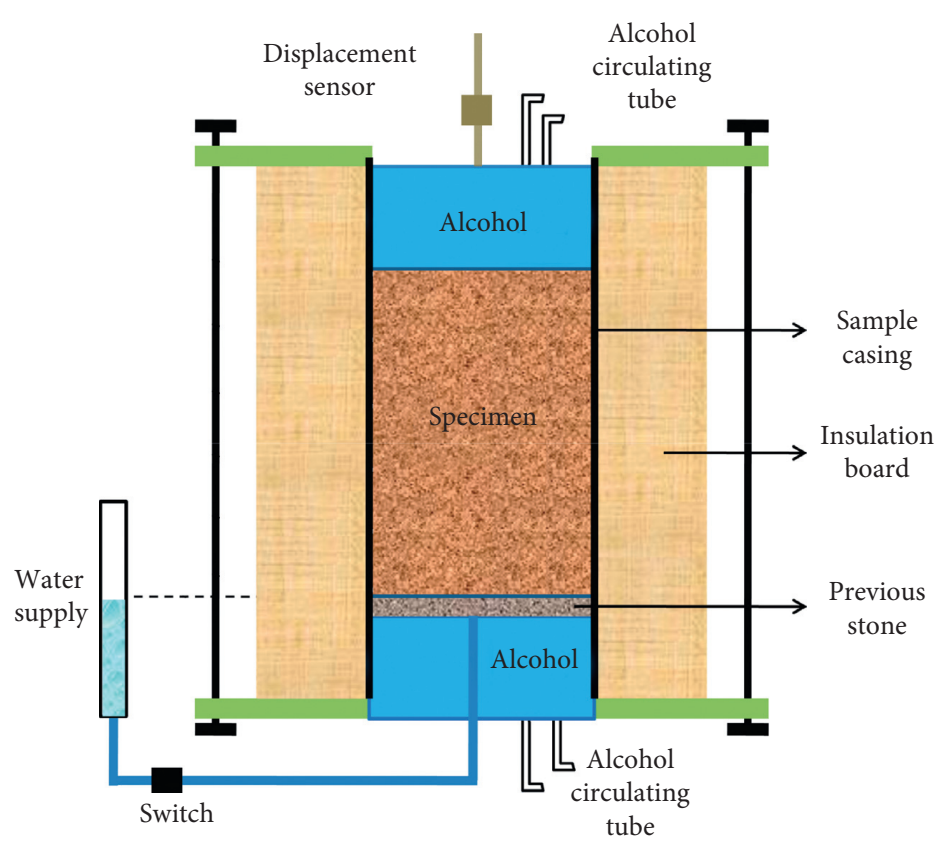

(b)

Figure 1: Apparatus for the freeze-thaw test: (a) schematic diagram; (b) environmental chamber.

TABLe 2: Experimental scheme of the triaxial compression test.

\begin{tabular}{lcccc}
\hline $\begin{array}{l}\text { Initial dry density } \\
\left(\mathrm{g} / \mathrm{cm}^{3}\right)\end{array}$ & Initial moisture content $(\%)$ & Confining pressure $(\mathrm{kPa})$ & Temperature range $\left({ }^{\circ} \mathrm{C}\right)$ & Number of freeze-thaw cycles \\
\hline 1.50 & 20.2 & $50,100,150$ & \pm 30 & 3 \\
& 18.2 & $50,100,150$ & \pm 30 & 3 \\
1.57 & 20.2 & $50,100,150$ & $\pm 30, \pm 20, \pm 10, \pm 5$ & $0,1,3,5,7$ \\
& 22.2 & $50,100,150$ & \pm 30 & 3 \\
1.63 & 20.2 & $50,100,150$ & \pm 30 & 3 \\
\hline
\end{tabular}

\section{Results and Discussion}

3.1. Elastic Modulus. The elastic modulus is defined as the ratio of the increment of deviator stress to the increment of axial strain when the axial strain is $1 \%$ of the three axial compression test, which can be expressed by

$$
E=\frac{\Delta \sigma}{\Delta \varepsilon}=\frac{\sigma_{1.0 \%}-\sigma_{0}}{\varepsilon_{1.0 \%}-\varepsilon_{0}},
$$

where $\Delta \sigma$ is the increment of deviator stress, $\Delta \varepsilon$ is the increment of axial strain, $\sigma_{1.0 \%}$ is the corresponding deviator stress at the axial strain of $1.0 \%$, and $\sigma_{0}$ and $\varepsilon_{0}$ are the initial stress and strain, respectively [16].

The variations of elastic modulus of specimens with different freeze-thaw cycles under 3 confining pressures are shown in Figure 2. The elastic modulus decreases with the increase of freeze-thaw cycles and changes little after 3 freeze-thaw cycles. The maximum reduction occurs after the first freeze-thaw cycle. The elastic modulus decreases by about $90 \%$ when it reaches stability. The effects of various factors on the elastic modulus of soil were analyzed by the results of 3 freeze-thaw cycles in the following sections.
Figures 3 and 4, respectively, describe the influence of initial dry density and initial moisture content on the elastic modulus of soil after freeze-thaw cycles. It can be seen that the elastic modulus increases approximately linearly with the increase of initial dry density and moisture content, even with different confining pressure. However, the effect of increasing soil dry density on the elastic modulus is more significant.

Figure 5 illustrates the elastic modulus of specimens after freeze-thaw cycles under different temperature ranges. It is obvious from Figure 5 that when the temperature range varies from $\pm 5^{\circ} \mathrm{C}$ to $\pm 20^{\circ} \mathrm{C}$, the elastic modulus of the specimens changes very little. However, the elastic modulus increases significantly once the temperature range changes to $\pm 30^{\circ} \mathrm{C}$.

3.2. Cohesion and Friction Angle. According to the actual temperature distribution of the levee, the change of the cohesion and the internal friction angle with the number of freeze-thaw cycles was investigated under the condition of 4 kinds of temperature ranges. The results are shown in Figures 6 and 7, respectively. The cohesion and internal 


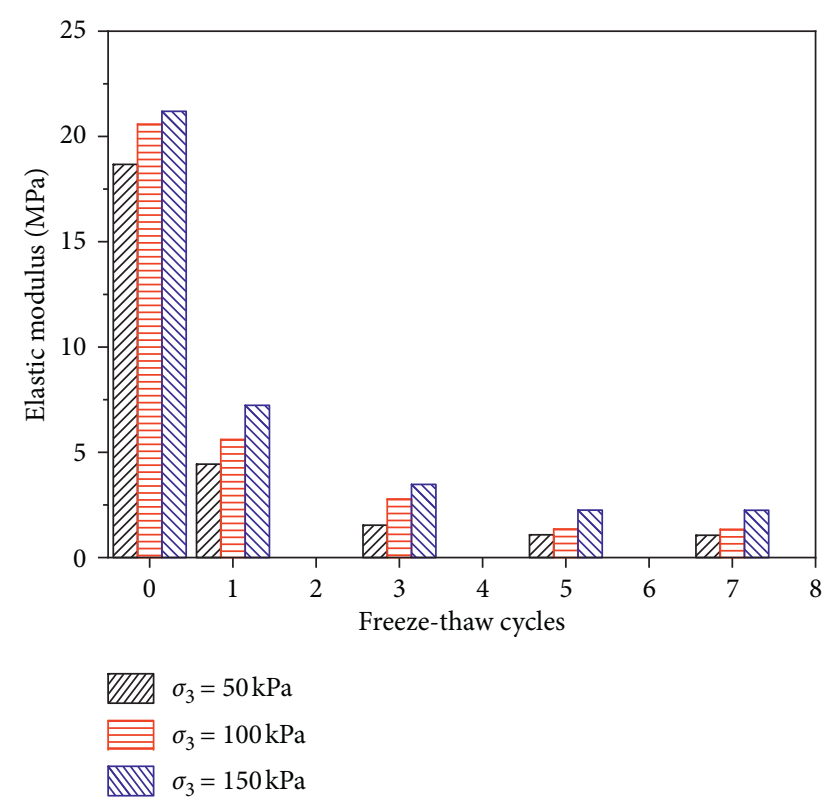

Figure 2: Variation of elastic modulus with the number of freezethaw cycles.

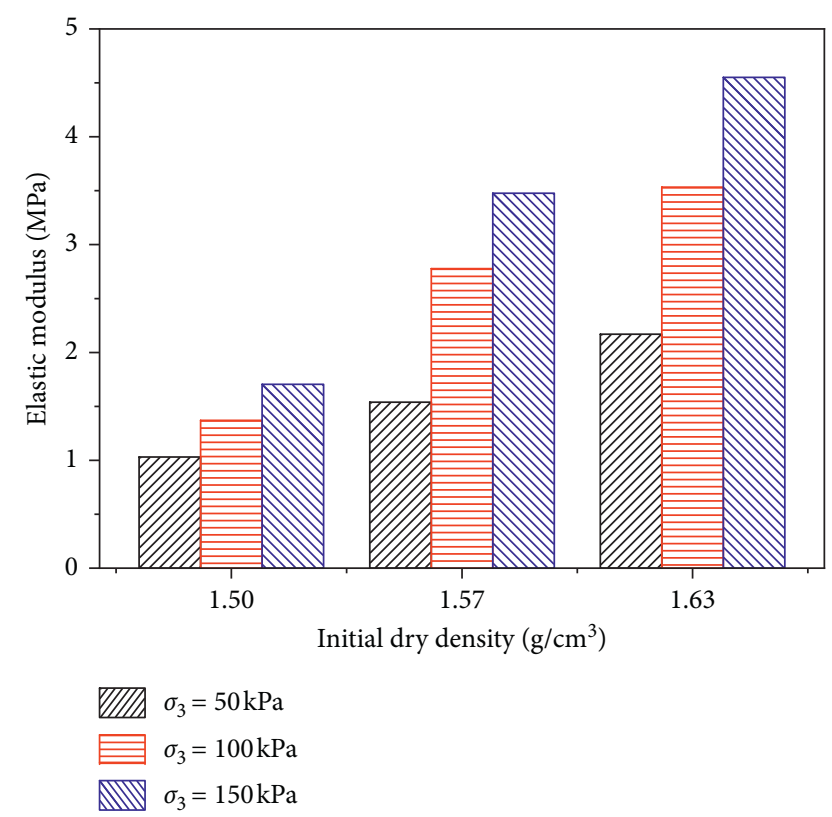

FIGURE 3: Variation of elastic modulus with the initial dry density.

friction angle decrease with the increase of freeze-thaw cycles and stabilize gradually with different temperature ranges. The cohesion reaches a stable state after 3 freezethaw cycles, while the internal friction angle gradually stabilizes after 5 cycles. The decrease of cohesion is about $90 \%$, and the decrease of the internal friction angle is between $64 \%-90 \%$ after 7 freeze-thaw cycles, which indicates that the freeze-thaw deterioration effect of the external environment is more significant on cohesion. Moreover, the differentiation of cohesion and internal friction angle caused by different temperature ranges is remarkable.

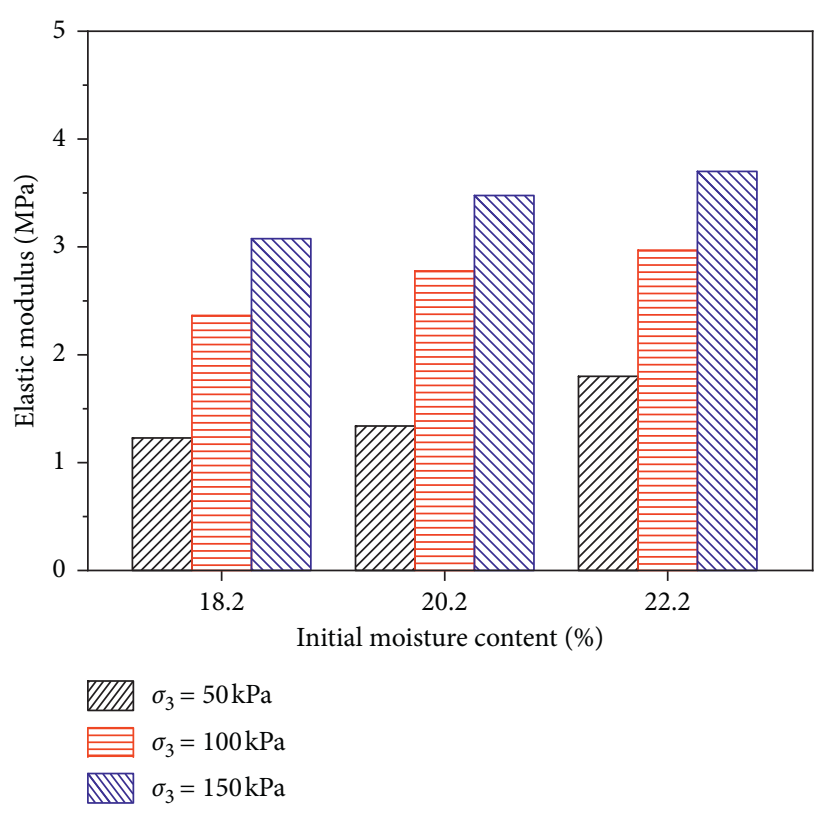

FIGURE 4: Variation of elastic modulus with the initial moisture content.

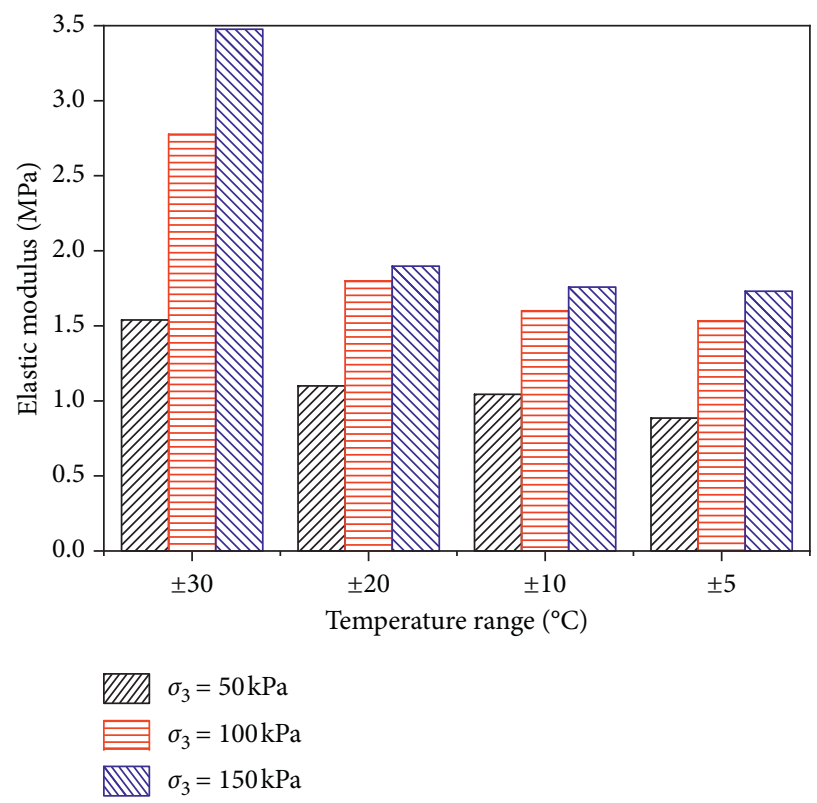

Figure 5: Variation of elastic modulus with different temperature ranges.

\section{Analysis of Mechanical Response in Pavement}

4.1. Mechanical Response of Pavement Structure. The horizontal stress of its structure determines the service life of the pavement. The increase of tensile stress at the bottom of the surface will shorten the fatigue life of the pavement. Cracks at the base when the bottom tensile stress exceeds its tensile strength will result in reflection cracks on the asphalt surface. The compressive strain at the top of the subgrade is an important index to control the permanent deformation of 


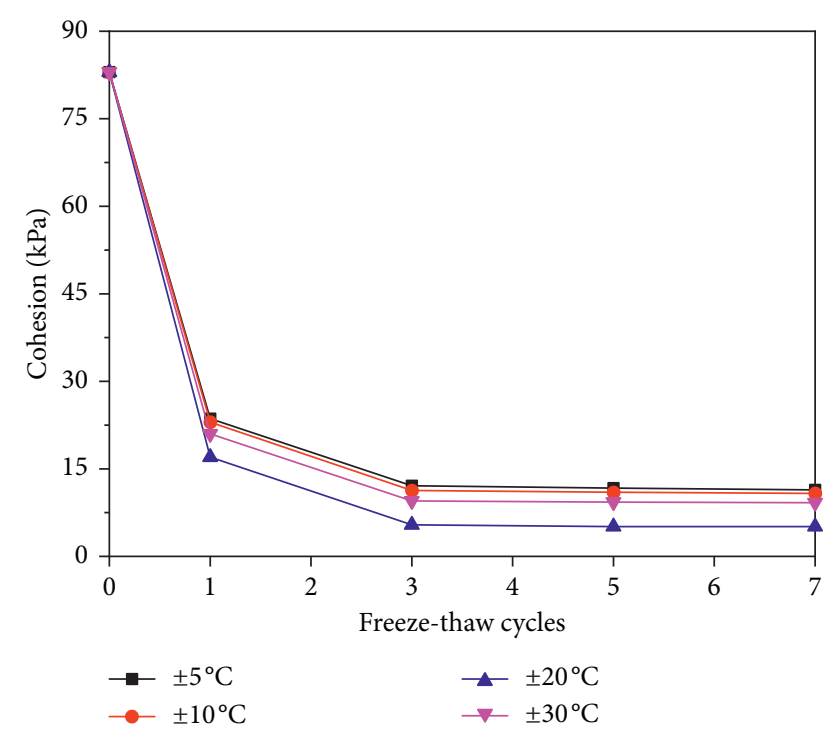

FIgURE 6: Variation of cohesion with the number of freeze-thaw cycles.

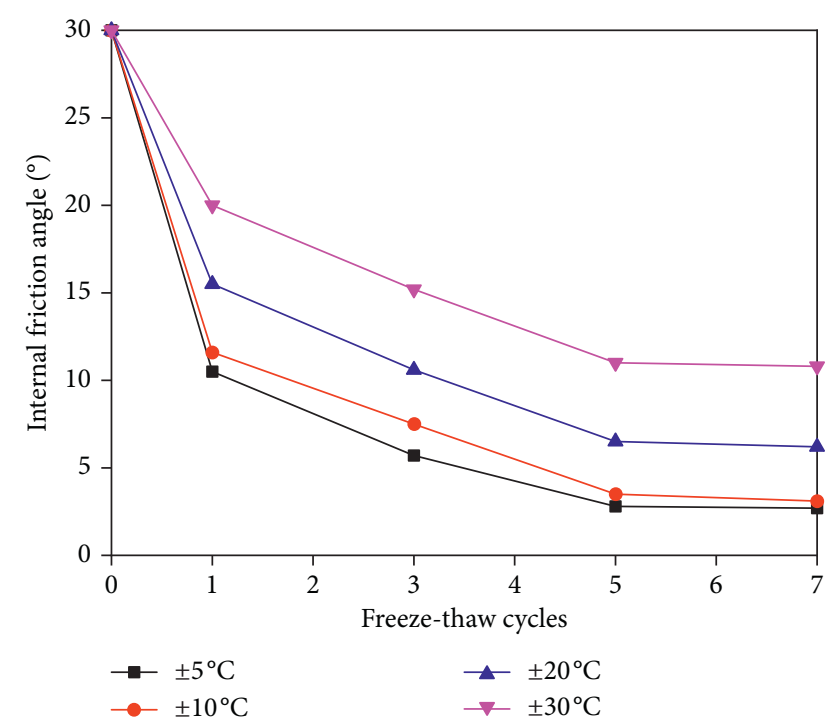

FIGURE 7: Variation of internal friction angle with the number of freeze-thaw cycles.

the granular base and the rutting of the pavement. BISAR 3.0 is a calculation system for asphalt pavement structure, and it can calculate the stress, strain, and displacement of elastic layered system under different kinds of static loads. In this paper, BISAR 3.0 was adopted to analyze the maximum tensile stress and strain in the bottom of surface and subbase course, the maximum compressive stress and strain at the top of the embankment, and the maximum deflection of pavement with the dual-wheel single-axle load of $100 \mathrm{kN}$ as an example.

A simplified model of pavement-embankment interaction was established, as shown in Figure 8. The base course and subbase course were merged into a single layer as they were relatively thin with similar material properties [9]. The

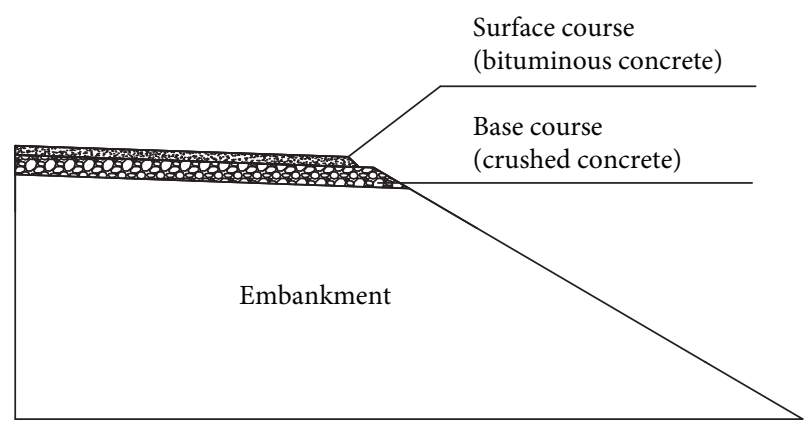

FIGURE 8: Schematic diagram of the pavement-embankment structure.

main calculation parameters are shown in Table 3 [17]. Since pavement structure responses were calculated after thawing, we assumed that the modulus of the surface and base materials were constant. The elastic modulus of embankment soils was the experimental results with the confining pressure of $50 \mathrm{kPa}$.

4.2. Influence of Freeze-Thaw Cycles. The mechanical response of pavement structure caused by the degradation of soil mechanical properties induced by different freeze-thaw cycles is shown in Figure 9. Figures 9(a) and 9(b) indicate that the maximum horizontal tensile stress and tensile strain at the bottom of the surface and base both increase first and then stabilize with the increase of freeze-thaw cycles contrary to the elastic modulus of soil. The variation of tensile stress and tensile strain at the bottom of the base is larger than that of the surface, with a doubling in the amount. Therefore, the freeze-thaw cycles have a greater impact on the internal force of the base layer. The variation of maximum compressive stress at the top of the embankment is similar to the soil modulus and decreases significantly and then gradually stabilizes with a final decrease of $85 \%$. Quite the contrary, the peak strain at the top of the embankment increases first and then gradually stabilized with an increase of $120 \%$ (Figure 9(c)). These suggest that the tensile stress of the surface layer and base is consistent with the tensile strain, while the variation trend of compressive stress and compressive strain at the top of the embankment is opposite. Figure 9(d) shows that the maximum deflection increases with the increase of freeze-thaw cycles and tends to be stable after the 5 cycles. After 7 cycles, the deflection increases by 5 times than that before freezing and thawing. And, the pavement deflection is mainly caused by the deformation of the embankment soil, so the control of the deformation of the compacted soil of embankment plays a key role in ensuring the smoothness of the pavement.

4.3. Influence of Initial Dry Density. The effect of initial dry density on the mechanical response of pavement structure is shown in Figure 10. It can be seen that the stress-strain of each structural layer and deflection vary linearly with the change of dry density. Although the tensile stress and tensile strain at the bottom of each structural layer decrease with the 
TABLE 3: Material parameters of each structural layer.

\begin{tabular}{lcccc}
\hline Layer & Thickness $(\mathrm{m})$ & Density $\left(\mathrm{kg} / \mathrm{m}^{3}\right)$ & Elastic modulus $(\mathrm{MPa})$ & Poisson's ratio \\
\hline Surface course & 0.15 & 2100 & 9150 & 0.33 \\
Base course & 0.4 & 1800 & 200 & 0.5 \\
Embankment & - & $\rho$ & Varied & 0.4 \\
\hline
\end{tabular}

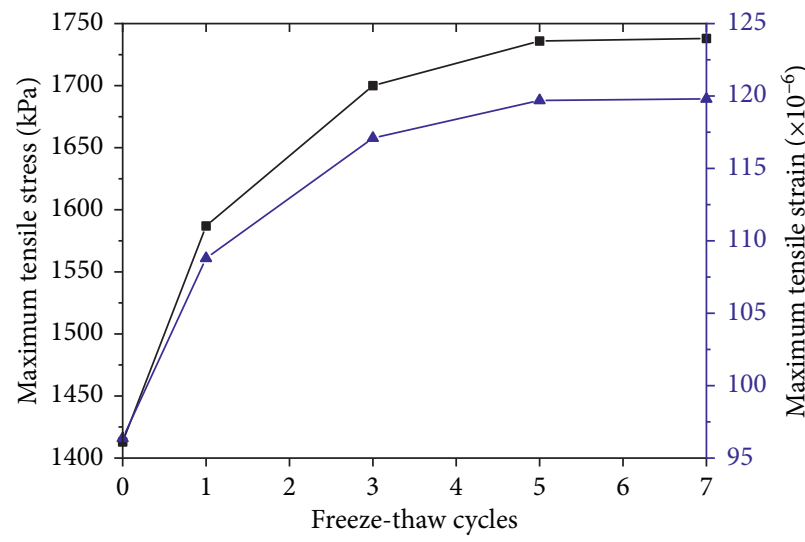

$$
\rightarrow \text { Stress }
$$$$
₫ \text { Strain }
$$

(a)

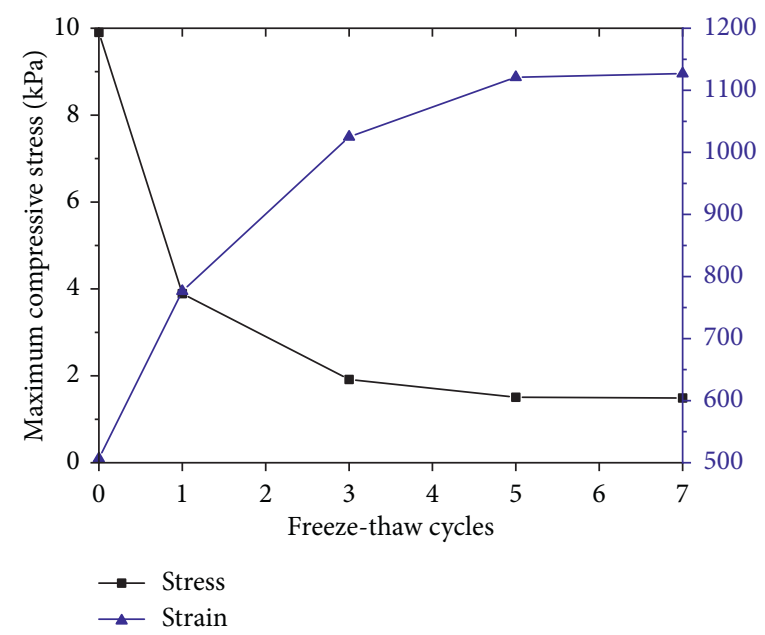

(c)

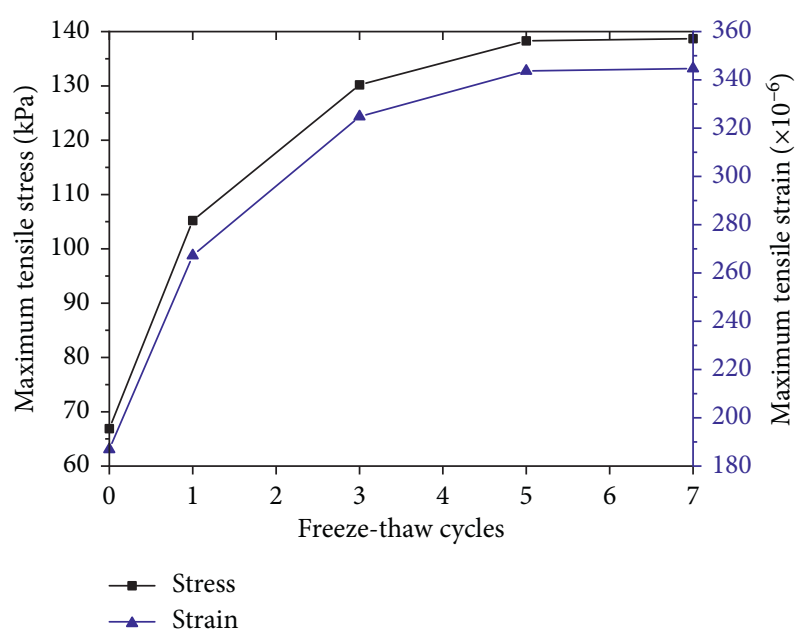

(b)

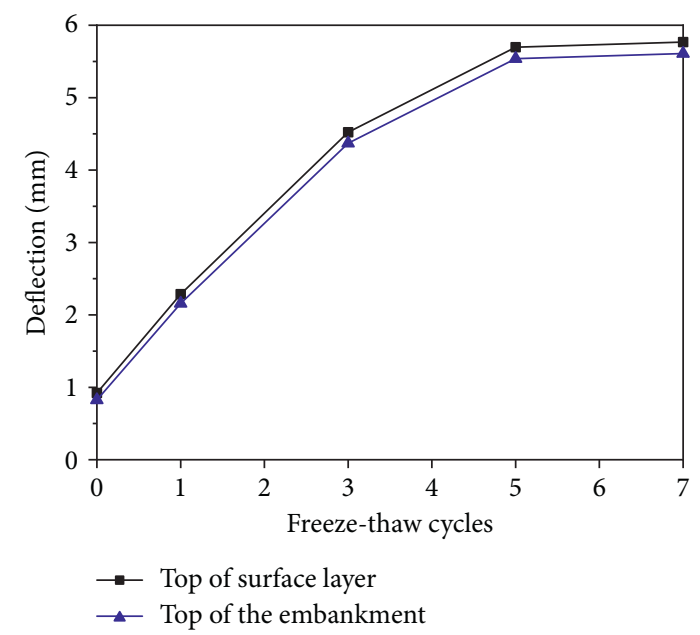

(d)

Figure 9: Mechanical response of pavement structure under different freeze-thaw cycles: (a) bottom of surface, (b) bottom of base, (c) top of the embankment, (d) deflection of the pavement.

increase of dry density, the mechanical response of the surface layer and the base is not significant (Figures 10(a) and $10(b))$. However, the increase of compressive stress at the top of the embankment reaches $65 \%$, and the corresponding strain reduction is only $17 \%$ (Figure 10(c)). The pavement deflection decreases by about $40 \%$ when the embankment soil density increases from $1.50 \mathrm{~g} / \mathrm{cm}^{3}$ to $1.63 \mathrm{~g} / \mathrm{cm}^{3}$ (Figure $10(\mathrm{~d})$ ).

4.4. Influence of Initial Moisture Content. The effect of initial moisture content on the mechanical response of pavement structure is shown in Figure 11. Similar to the situation affected by dry density, the mechanical response of the surface layer and the base changes little in magnitude (Figures 11(a) and 11(b)), but as a whole, the tensile stress and tensile strain at the bottom of each structural layer decrease with the increase of moisture content. When the moisture content of embankment soil increases from 18.2\% to $22.2 \%$, the increase of compressive stress at the top of the embankment is $30 \%$ and the corresponding strain reduction is only $9 \%$ (Figure 11(c)). Meanwhile, the pavement deflection decreases by $20 \%$ (Figure $11(\mathrm{~d})$ ). It indicates that the influence of moisture content of embankment soil on the mechanical response of pavement is less than that of soil dry density. 


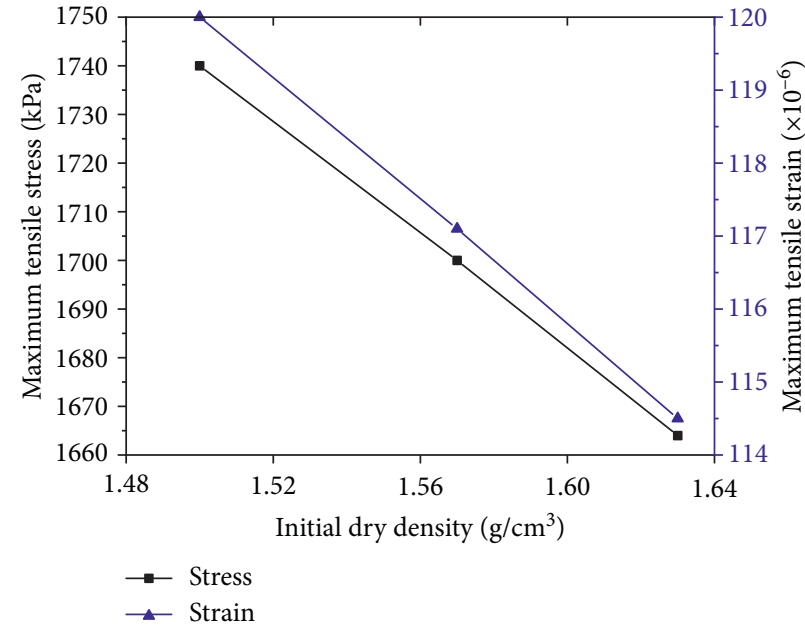

(a)

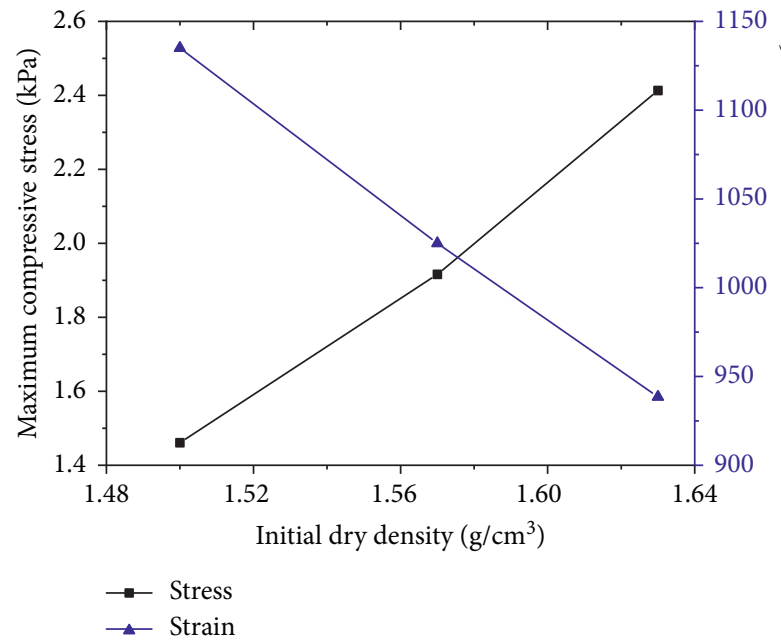

(c)

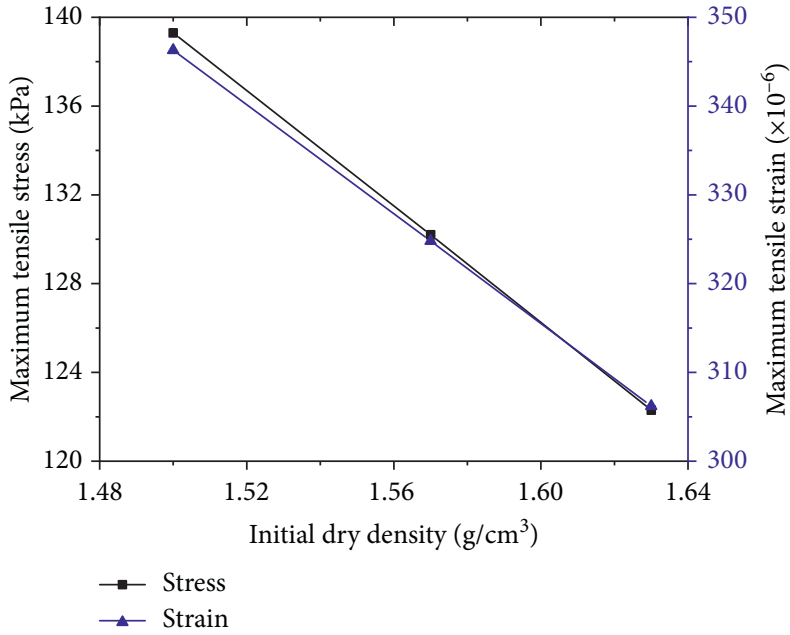

(b)

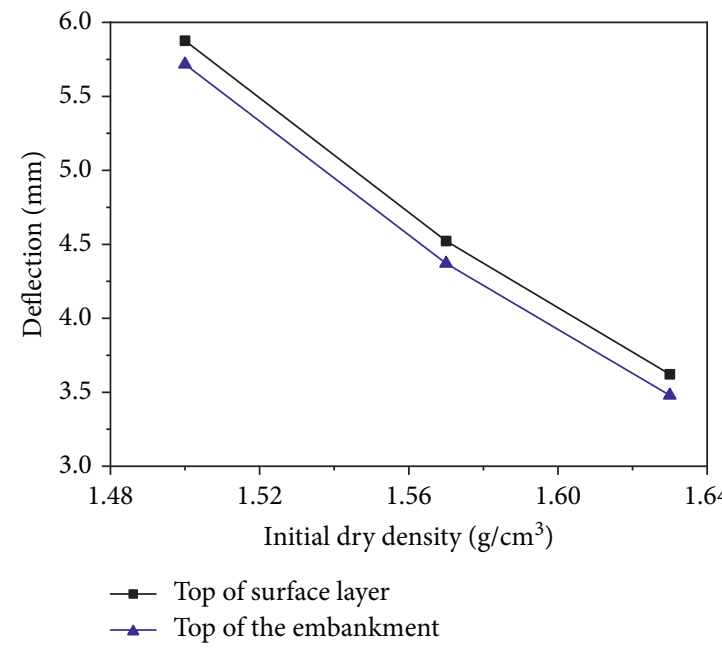

(d)

FIGURE 10: Mechanical response of pavement structure under different initial dry densities: (a) bottom of surface, (b) bottom of base, (c) top of the embankment, (d) deflection of the pavement.

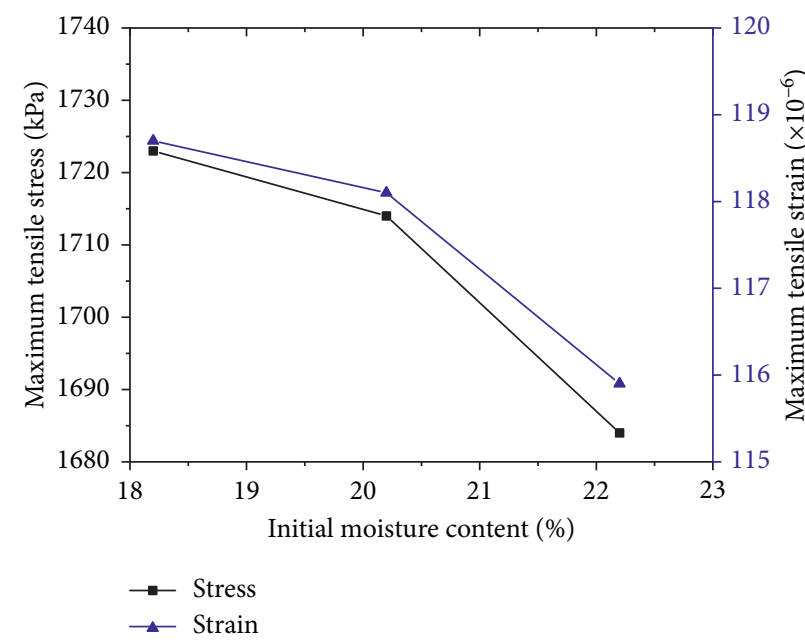

(a)

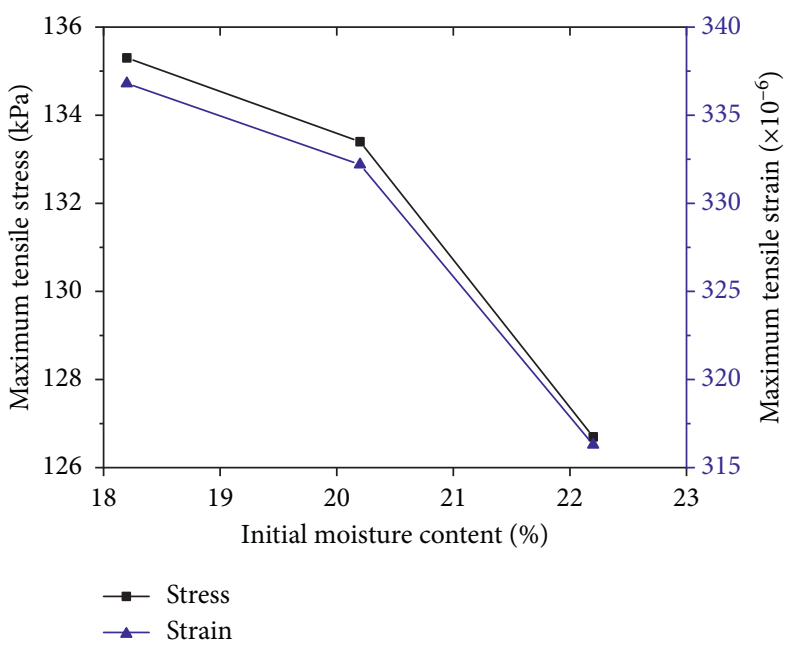

(b)

FIgUre 11: Continued. 


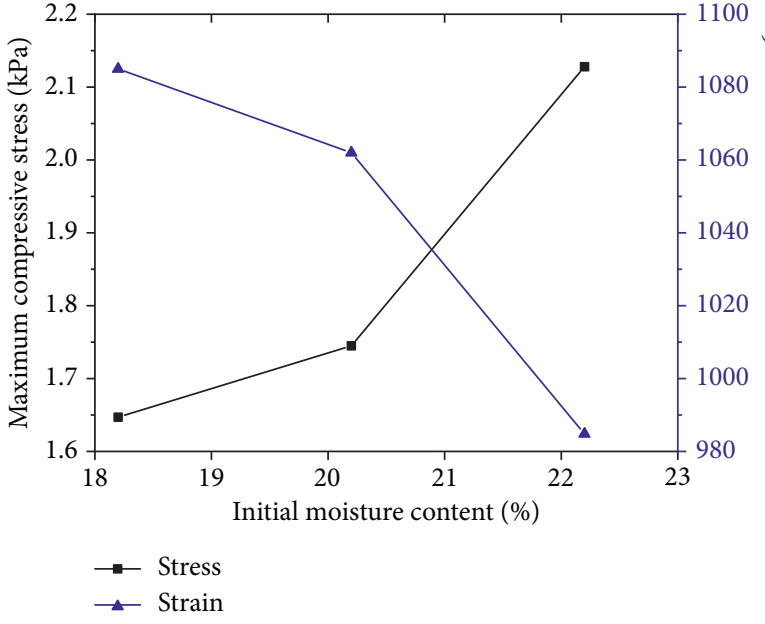

(c)

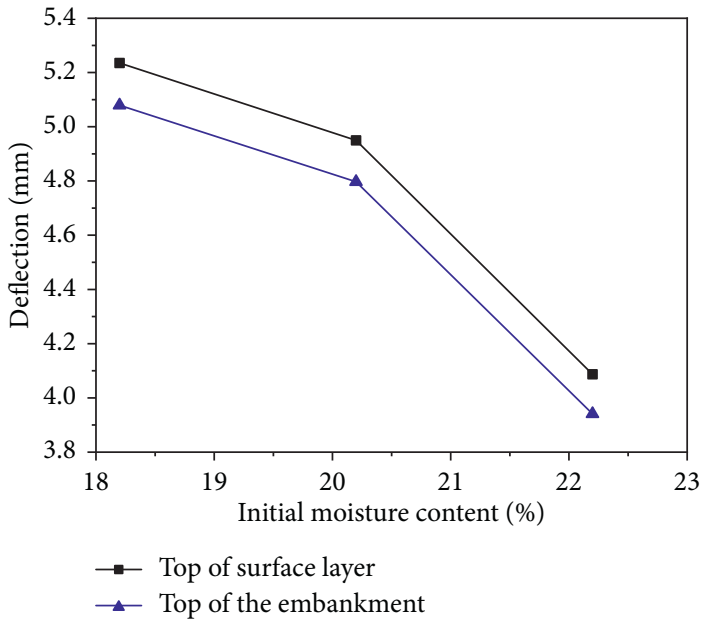

(d)

FiguRE 11: Mechanical response of pavement structure under different initial dry densities: (a) bottom of surface, (b) bottom of base, (c) top of the embankment, (d) deflection of the pavement.

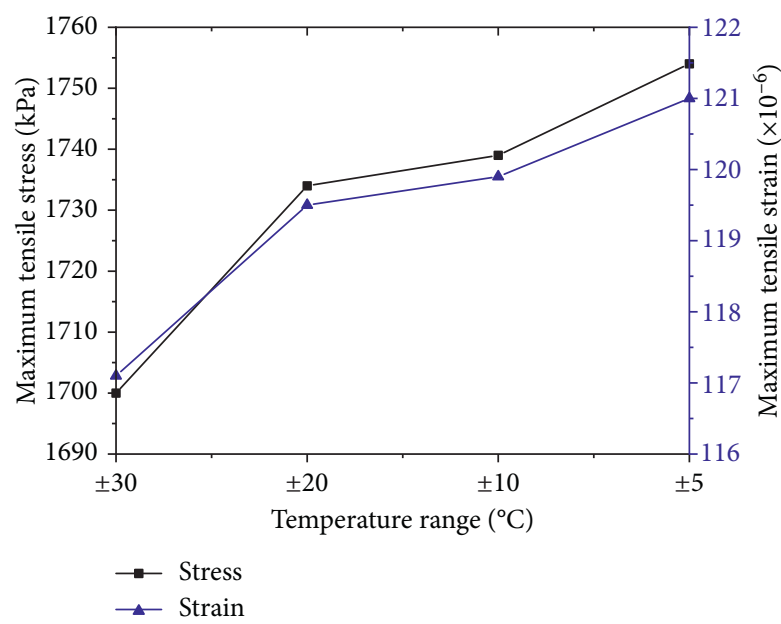

(a)

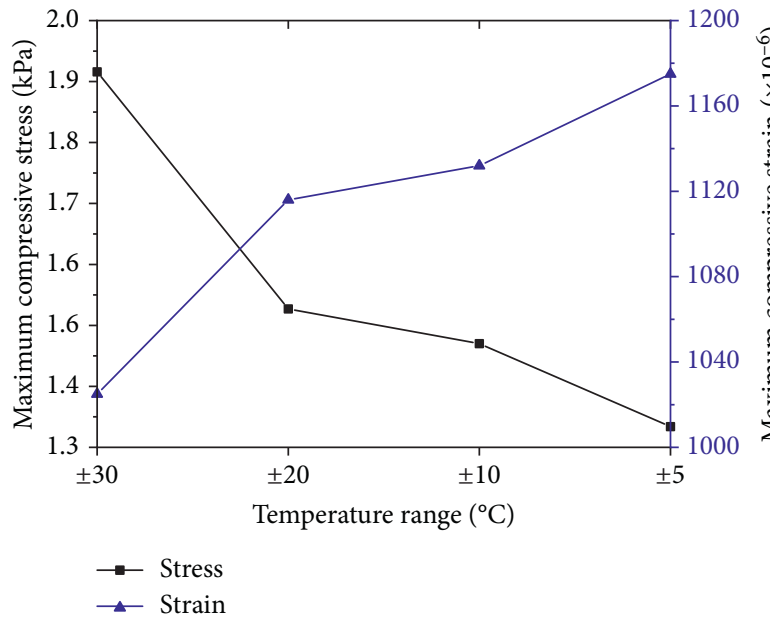

(c)

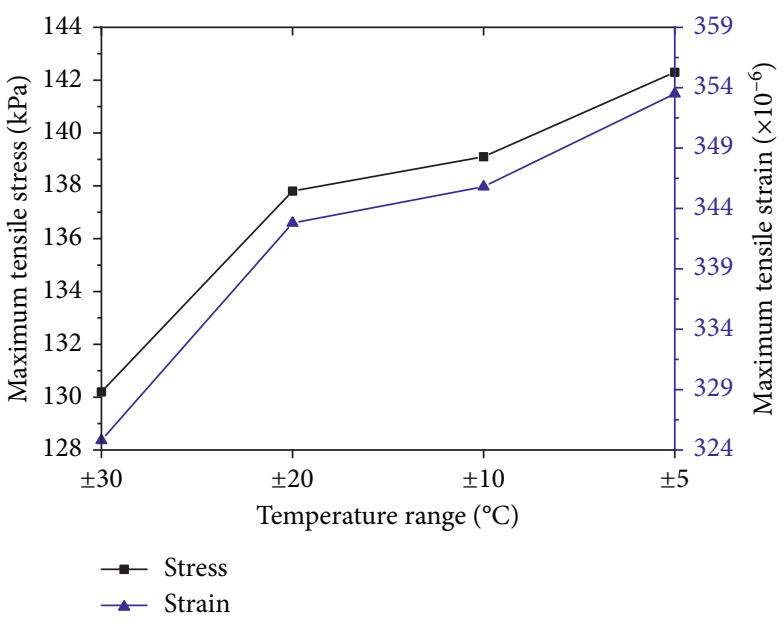

(b)

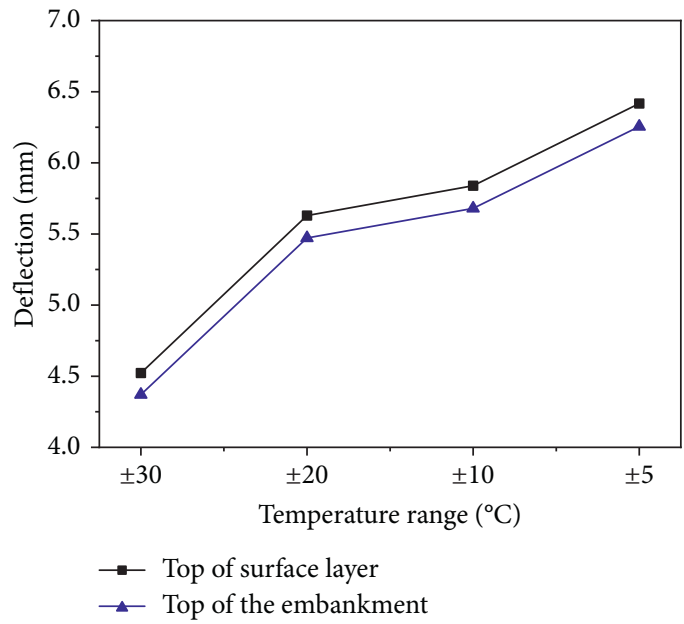

(d)

FIGURE 12: Mechanical response of pavement structure under different temperature ranges: (a) bottom of surface, (b) bottom of base, (c) top of the embankment, (d) deflection of the pavement. 
4.5. Influence of Temperature Range. The mechanical response of pavement structure caused by the degradation of soil mechanical properties induced by different temperature ranges is shown in Figure 12. As can be seen from Figure 12, the mechanical property and deformation of the various structural layers change significantly when the temperature range increases to $\pm 30^{\circ} \mathrm{C}$ and change little for the temperature range less than $\pm 30^{\circ} \mathrm{C}$.

\section{Conclusion}

In the present study, the variations of elastic modulus, cohesion, and internal friction angle of the soil after freezing and thawing cycles are investigated by freeze-thaw tests and triaxial compression tests. Based on the experimental data, the pavementembankment interaction has been studied by calculation, considering the deterioration of soil caused by freeze-thaw cycles. Although the experiment was performed on a single kind of soil in the mainstream of Songhua River, the variation law obtained from experiment results has some degree of universality. However, further verification should be conducted by a series of field monitoring data. From the experimental results and the calculation results, the major conclusions can be drawn:

(1) The freeze-thaw cycles and initial dry density significantly affect the elastic modulus of the soil. When the temperature exceeds a certain threshold, the elastic modulus will be affected obviously by the temperature range. The cohesion and internal friction angle vary greatly due to the different temperature ranges.

(2) The number of freeze-thaw cycles has a great influence on the mechanical response of pavement. Tensile stress and strain at the bottom of the surface and base both increase firstly and then stabilize with the increase of freeze-thaw cycles. After 7 cycles, the tensile stress and tensile strain at the bottom of the base double, the maximum compressive stress at the embankment top decreases by $85 \%$, while the maximum pressure strain increases by $120 \%$. And, the pavement deflection increases by 5 times than that before freeze-thaw cycles.

(3) The stress-strain of each structural layer and deflection varies linearly with the change of soil dry density. Moreover, the dry density has little influence on the mechanical indexes of the surface and base course but greatly influences the mechanical indexes and deformation of the embankment.

(4) The influence of moisture content of embankment soil on the mechanical response of pavement is less than that of soil dry density. The mechanical property and deformation of the various structural layers change significantly when the temperature range exceeds $\pm 20^{\circ} \mathrm{C}$.

\section{Data Availability}

The data used to support the findings of this study are available from the corresponding author upon request.

\section{Conflicts of Interest}

The authors declare that they have no conflicts of interest.

\section{Acknowledgments}

This work was supported by the National Natural Science Foundation of China (Nos. 42077262, 42077261, and 41972294) and Hunan Transportation Science and Technology Foundation (Nos. 201706 and 201826).

\section{References}

[1] J.-M. Konrad and M. Roy, "Flexible pavements in cold regions: a geotechnical perspective," Canadian Geotechnical Journal, vol. 37, no. 3, pp. 689-699, 2000.

[2] A. Khan, D. Mrawira, and E. E. Hildebrand, "Use of lightweight aggregate to mitigate frost damage in flexible pavements," International Journal of Pavement Engineering, vol. 10, no. 5, pp. 329-339, 2009.

[3] C. Li, P. K. R. Vennapusa, J. Ashlock, and D. J. White, "Mechanistic-based comparisons for freeze-thaw performance of stabilized unpaved roads," Cold Regions Science and Technology, vol. 141, pp. 97-108, 2017.

[4] E. Özgan and S. Serin, "Investigation of certain engineering characteristics of asphalt concrete exposed to freeze-thaw cycles," Cold Regions Science and Technology, vol. 85, pp. 131-136, 2013.

[5] S.-M. Kim and B. F. McCullough, "Dynamic response of plate on viscous Winkler foundation to moving loads of varying amplitude," Engineering Structures, vol. 25, no. 9, pp. 1179-1188, 2003.

[6] V. C. Janoo and R. L. Berg, "PCC airfield pavement response during thaw-weakening periods," Journal of Cold Regions Engineering, vol. 12, no. 3, pp. 138-151, 1998

[7] E. Simonsen, V. C. Janoo, and U. Isacsson, "Resilient properties of unbound road materials during seasonal frost conditions," Journal of Cold Regions Engineering, vol. 16, no. 1, pp. 28-50, 2002.

[8] E. Simonsen and U. Isacsson, "Thaw weakening of pavement structures in cold regions," Cold Regions Science and Technology, vol. 29, no. 2, pp. 135-151, 1999.

[9] F. Salour and S. Erlingsson, "Investigation of a pavement structural behaviour during spring thaw using falling weight deflectometer," Road Materials and Pavement Design, vol. 14, no. 1, pp. 141-158, 2013.

[10] D. T. Jong, P. J. Bosscher, and C. H. Benson, "Field assessment of changes in pavement moduli caused by freezing and thawing," Transportation Research Record: Journal of the Transportation Research Board, vol. 1615, no. 1, pp. 41-48, 1998.

[11] W. Lee, N. C. Bohra, A. G. Altschaeffl, and T. D. White, "Resilient modulus of cohesive soils and the effect of freezethaw," Canadian Geotechnical Journal, vol. 32, no. 4, pp. 559-568, 1995.

[12] W. Wang, Y. Qin, M. Lei, and X. Zhi, "Effect of repeated freeze-thaw cycles on the resilient modulus for fine-grained subgrade soils with low plasticity index," Road Materials and Pavement Design, vol. 19, no. 4, pp. 898-911, 2018.

[13] K. Hazirbaba and H. Gullu, "California bearing ratio improvement and freeze-thaw performance of fine-grained soils treated with geofiber and synthetic fluid," Cold Regions Science and Technology, vol. 63, no. 1-2, pp. 50-60, 2010. 
[14] Y. Zhang, A. E. Johnson, and D. J. White, "Laboratory freezethaw assessment of cement, fly ash, and fiber stabilized pavement foundation materials," Cold Regions Science and Technology, vol. 122, pp. 50-57, 2016.

[15] C. Zhou, B. Huang, E. Drumm, X. Shu, Q. Dong, and S. Udeh, "Soil resilient modulus regressed from physical properties and influence of seasonal variation on asphalt pavement performance," Journal of Transportation Engineering, vol. 141, 2015.

[16] L. Tang, S. Cong, L. Geng, X. Ling, and F. Gan, "The effect of freeze-thaw cycling on the mechanical properties of expansive soils," Cold Regions Science and Technology, vol. 145, pp. 197-207, 2018.

[17] G. Lombaert and G. Degrande, "The experimental validation of a numerical model for the prediction of the vibrations in the free field produced by road traffic," Journal of Sound and Vibration, vol. 262, no. 2, pp. 309-331, 2003. 